\title{
A Structured Outsourcing Procedure
}

\author{
Maria Flavia Mogos ${ }^{1}$, Børge Sjøbakk ${ }^{2}$, and Erlend Alfnes ${ }^{1}$ \\ 1 Norwegian University of Science and Technology (NTNU), Trondheim, Norway \\ \{maria.f.mogos, erlend.alfnes\}@ntnu.no \\ 2 SINTEF Technology and Society, Trondheim, Norway \\ borge.sjobakk@sintef .no
}

\begin{abstract}
Outsourcing of production entails a vast amount of activities and decisions. Although it has many acknowledged benefits, it is associated with substantial risk, and may lead to increased costs and loss of business if it is not carried out carefully and in a systematic manner. The identified outsourcing literature mainly focuses on specific parts of the outsourcing process and often provides limited practical guidance. Therefore, the purpose of this paper is to synthesize existing research on outsourcing processes into one structured outsourcing procedure. This can guide companies in carrying out outsourcing activities in a systematic manner. The suggested procedure is discussed in light of a case study of two production transfers between a Norwegian supplier of advanced maritime monitoring systems and one of its strategic suppliers.
\end{abstract}

Keywords: Outsourcing. Production transfer. Operations strategy

\section{Introduction}

Many Western companies choose to transfer parts of their production to other actors in their supply chains. Such transfers are often denoted outsourcing or offshoring processes, depending on the ownership structure (internal or external) and target location (domestic or foreign) of the transfer [1]. Outsourcing generally refers to the handover of responsibility for certain activities across organizational borders, whereas offshoring indicates that the responsibility is transferred to a subsidiary or supplier in a foreign location. Due to its many stated benefits, such as lower factors costs, access to new materials, distribution channels and technologies, as well as increased capacity to focus on core competences, outsourcing has been a very popular strategy in many industries [2]. Still, it is associated with substantial risk and may lead to increased costs and loss of business if it is not carried out carefully and in a systematic manner reflecting the high complexity of such transfer processes [2].

Outsourcing of production entails a vast amount of decisions to be taken. Although several outsourcing frameworks and guidelines exist, only a few [e.g. $[3,4]]$ describe all stages of the outsourcing process. These are typically rather general in their description of the activities that need to be carried out at the different stages. More detailed frameworks typically focus on the make-or-buy 
phase of the process, by e.g. discussing possible benefits and risks when outsourcing [5], or they end before the physical transfer [6]. Frameworks that address the production transfer $(\mathrm{PT})$, i.e. the actual relocation of manufacturing of products or components between two production facilities (Sender and Receiver), either focus on specific parts of the PT [6], or provide only a general overview of interdependent activities important for supply performance $[3,7,8]$. No comprehensive frameworks integrating all these aspects have been identified. Therefore, the purpose of this paper is to synthesize existing research on outsourcing processes into one structured outsourcing procedure. This can guide companies in carrying out outsourcing activities in a systematic manner. The procedure is discussed in light of an instrumental case study of two PTs between a Norwegian supplier of advanced maritime monitoring systems and one of its strategic suppliers within electronic manufacturing services (EMS).

\section{Research Method}

The structured outsourcing procedure is proposed on the basis of a thorough study of literature on production-, knowledge-, and technology-transfers, as well as more general literature on outsourcing, production start-up and ramp-up. When structuring the literature, the most comprehensive identified models and methods $[3,4,5]$ were taken as a starting point. During the structuring of the literature a need to add, rearrange and adjust phases emerged - more or less resulting in the proposed procedure. However, an instrumental case study approach [9] has been selected to test and accomplish it. This was designed as a single case study as the access to adequate empirical data was limited to one supplierbuyer relation; however, two PTs were followed to increase the research quality. The empirical data was collected through workshops and semi-structured interviews with key representatives from both case companies, e.g. quality managers, product developers, key account managers and process engineers.

\section{Structuring Outsourcing}

In broad terms the production outsourcing process can be divided into three parts: (1) deciding what (if any) to outsource, (2) selecting and committing a supplier, and (3) transferring the production. Each of these contains a number of activities that a company needs to go through during an outsourcing process. These are briefly described and summarized below. IDs are assigned to the activities, in order to link them to the suggested outsourcing procedure at the end of the section.

\subsection{The Outsourcing Decision}

In describing the outsourcing decision, a framework by Kremic et al. [5] is adopted. This depicts typical elements of the outsourcing decision, and shows 
where motivators, benefits, risks and other factors are typically encountered. The first step is to consider outsourcing in the first place. Here, the sender's motivation for outsourcing is weighed against general risks and benefits. According to [5] (a combination of) three major categories of motivation drives outsourcing: cost, strategy, and politics. The sender should have a conscious attitude towards these (A1). For instance, the outcome of outsourcing is often more successful if the decision is based on strategic considerations rather than solely on financial problems [10]. Further, the sender should analyze whether common benefits and risks of outsourcing either strengthen or weaken the decision (A2). Although it is not explicitly stated in the literature, we suggest documenting (A3) and communicating (A4) the resulting outsourcing policy internally. Next, the sender should identify (A5), evaluate (A6) and select (A7) what, if any, to outsource based on strategic-, financial-, functional- and environmental factors of each candidate and on the outsourcing policy [5]. When production is outsourced, Semini et al. [11] suggest careful attention to aspects such as logistics, equipment utilization, proximity to product development and intellectual property.

\subsection{Supplier Selection}

When the company has selected which functions, products or processes it should outsource, the next stage is to select a target supplier and location for the transfer. Here, a fourstage supplier selection process by Cousins et al. [12] is adopted. First, suppliers are prequalified (A8). Prequalification criteria will vary between companies and industries; however, suppliers' manufacturing capabilities and financial viability will usually be assessed. Often, companies keep a record of prequalified suppliers, enabling them to skip this phase. Otherwise, information about suppliers needs to be collected and evaluated. Next, the company should agree on measurement criteria (A9) that are specific to the product under consideration (e.g. unit price, lead time, supplier flexibility). Third, relevant information about suppliers should be gathered (A10), for example through requests for proposal or quotation. This information is used to make a selection in the fourth phase (A11). Danilovic and Winroth [13] argue that no matter how hard management strives to have a high level of integration in collaborative networks, the integration must be supported by legal agreements (A12). Draft agreements would often need to be designed for each case. Examples of issues that need to be included are forms of decision making, risk allocation, security issues and renegotiation/termination rules [13]. As will be evident in the next section, the contract may need to specify responsibilities before, during and after the transfer.

\subsection{Production Transfer}

Finally, when the receiving supplier has been selected the PT can commence. Based on [7], a PT process consists of four phases: the preparation for transfer, the physical transfer of equipment and inventories, the production start-up at Receiver, and the steady state. The Steady State starts after there has been 
reached a full-scale and stable production, at targeted levels of cost and quality [14]. Each of the PT related activities identified in the literature has been assigned to one of these four phases (Table 1).

Table 1. Overview of the studied production transfers and their main activities

\begin{tabular}{|c|c|}
\hline $\begin{array}{l}\text { Outsourcing policy: } \\
\text { A1. Identify the amou } \\
\text { and politically-driven o } \\
\text { A2. Analyze whether } \\
\text { or weaken the decision } \\
\text { A3. Establish policy do }\end{array}$ & $\begin{array}{l}\text { A24. Define Engineering Change process[14] } \\
\text { A25. Train Receiver's personnel [14,19]. } \\
\text { A26. Update/ create documentation with Receiver } \\
{[14,17,19] \text {. }} \\
\text { A27. Improve Receiver's performance }[20] \\
\text { A28. Update Planning \& Control system [17]. } \\
\text { A29. Develop Communication plan [4]. } \\
\text { A30. Transfer information [4]. } \\
\text { A31. Receiver reviews info. and finds gaps [4]. } \\
\text { A32. Ensure joint info. sharing platform [14]. } \\
\text { A33. Establish relations to sub-suppliers }[21] \\
\text { A34. Verify preparations [17]. } \\
\text { Physical Transfer: } \\
\text { A35. Transfer production equipment [7]. } \\
\text { A36. Send personnel to Receiver [14]. } \\
\text { A37. Install and test production equipment [7]. } \\
\text { Production Start-up: } \\
\text { A38. Sender temporary transfers personnel [14]. } \\
\text { A39. Set up experimental line [14]. } \\
\text { A40. Involve all affected personnel [7]. } \\
\text { A41. Qualify component vendors [14]. } \\
\text { A42. Decide when to transfer responsibility to order raw } \\
\text { material to Receiver [17]. } \\
\text { A43. Adapt processes to a new environment [22]. } \\
\text { A44. Problem solving on parts /materials[7]. } \\
\text { A45. Verify production [23]. } \\
\text { A46. Continuously monitor performance. Consider shut- } \\
\text { down when lower than targets to solve problems [14]. Im- } \\
\text { plement measures [17,24]. } \\
\text { A47. Adapt docs and Plan. \& Control syst. [17]. } \\
\text { A48. Conduct post-transfer audit. Evaluate transfer } \\
\text { [16,23]. } \\
\text { A49. Gen. sum. report (lessons learned, etc.) [4]. } \\
\text { Production Steady State: } \\
\text { A50. Continuously monitor and improve production [7]. }\end{array}$ \\
\hline
\end{tabular}

Apart from the Physical Transfer, a PT consists of three additional types of transfers: knowledge transfer (KT) (of tacit knowledge), administrative transfer (AT) (of explicit/codified knowledge), and supply chain transfer (SCT) (by establishing relations to vendors of materials)[25]. It is important to ensure all these types of transfers during a PT. In addition, transfer parties will have to perform certain project administrative activities, such as establishing a PT organization and manage the PT project [4].

The transfer preparation phase includes the most identified activities. Here, KT activities are mainly related to the training (A25) and involvement of Receiver personnel in the preparation of documentation, the systems, and of the production equipment and processes (A26). In addition, it might be necessary to implement KT activities for performance improvement at Receiver, such as six sigma or lean [20] (A27). AT activities are related to e.g. updating of planning and control systems with data based on the estimated lead times and other performance indicators for the PT [17] (A28), and the transfer of the updated information to Receiver (drawings, materials planning method, packaging procedures, etc.) (A30). SCT primarily concerns a possible transfer of suppliers to the Receiver (A33). Examples of project management (PM) activities are kick-off meeting (A14), signing of formal agreements (A16), and generating a transfer 
register with plans, flow diagrams, instructions and control procedures (accessible to both parties and up-to-date) (A20). The physical transfer mainly involves transfer of production equipment (A35), installation and testing of equipment (A36), but also certain KT by temporary transferring personnel from Sender to Receiver (A36) to provide support and report back to Sender [14]. Such a transfer can also take place during start-up (A38). Other KT activities during start-up imply setting up an experimental line for learning and for testing of performance improvement solutions at the Receiver (A39), and involving all the affected personnel along the process (A40). An AT task for the Receiver is to adapt documentation and systems to their own planning environment (A47). SCT activities during start-up are mainly related to qualification of component vendors (A41) and the decision about when to transfer the responsibility to order raw material to the Receiver (A42). As a PM activity, a summary report (A50) should be generated and stored in the transfer register.

\section{Discussion and Conclusions}

The empirical data collected during the case research is summarized in Table 2.

As seen in Table 2, Sender and Receiver had a series of challenges with the two PTs that might have been reduced by some of the actions from Table 1 . For instance, communicating the company's outsourcing policy internally (A4) and organizing a kick-off meeting where the reason for the PT is clarified (A14), could have increased the Product Team's motivation to share essential information with the Receiver in Case A [15]. The PT parties should have constituted a project team (A14), with PT managers and other members from all the affected disciplines and with clear roles [14]. Moreover, as stated by [4], PTs should be managed by help of a PM plan based on risk management principles (A20). Hence, all the activities with potentially negative consequences (e.g. transferring the test equipment to Receiver) should have been identified together with experienced personnel and measures should have been implemented (i.e. risk management) (A22). Further, some authors state that PTs, to the extent possible, should be planned as 'stepwise' transfers (A17) instead of 'clear-cut', as in Case A. Production at Sender should be gradually decreased as volumes increase at Receiver. Thus, in case of unexpected demand or major production disruptions during Start-up, one would have a secondary source of supply at the Sender [17]. Further, parties had several communication issues in both Case A and B. Thus, by preparing a communication plan (with e.g. points of contact and their roles) (A29), they could have minimized these challenges. This plan should be included in the PT register along with the PT plan and other tools, such as activities checklists, a change control system, and a flow diagram $[4,14]$. Moreover, the register should be continuously updated and an easily accessible to both parties (A20). Finally, at the end of the Start-up in Case A, Sender could have conducted a post-transfer audit, comparing the pre- and post-outsourcing costs [16] and evaluating whether the Steady-state had been achieved and whether the production should be relocated to other manufacturer or not (A48). In ad- 
Table 2. Overview of the studied production transfers and their main activities

\begin{tabular}{|c|c|}
\hline Completed transfer: Case A & Ongoing transfer: Case B \\
\hline 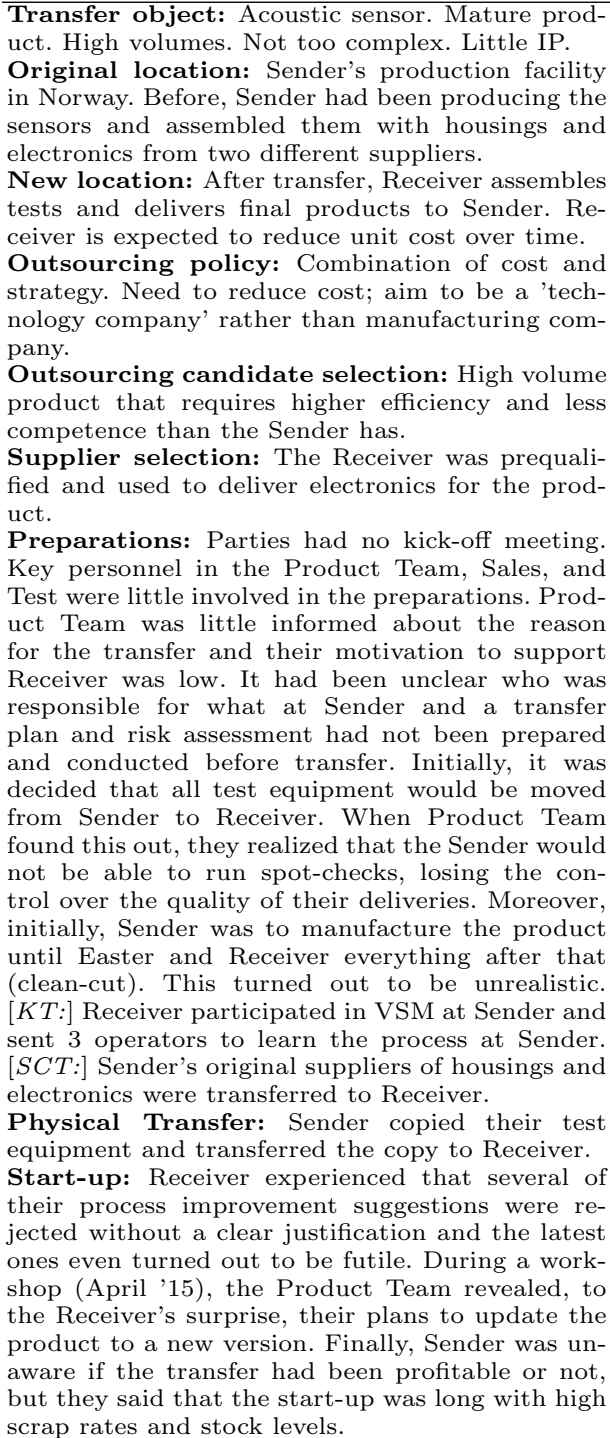 & $\begin{array}{l}\text { Transfer object: Signal converter. New version } \\
\text { of existing product. More complex than Product } \\
\text { A. } \\
\text { Original location: The same as in Case A. For } \\
\text { previous version, Sender installed PCBs from Re- } \\
\text { ceiver in cabinets from one supplier, and power } \\
\text { supply and wiring from another supplier. Sender } \\
\text { tested the final products. } \\
\text { New location: Same Receiver as in Case A. Af- } \\
\text { ter transfer, Receiver installs electronics includ- } \\
\text { ing own PCBs in cabinets. Sender still tests final } \\
\text { products. } \\
\text { Outsourcing policy: Same as in Case A. } \\
\text { Outsourcing candidate selection: Product } \\
\text { was selected due to the upcoming new version, } \\
\text { 'now was the time'. Key components were already } \\
\text { outsourced. } \\
\text { Supplier selection: Same as in Case A. Their } \\
\text { experience with product A was partly decisive. } \\
\text { Preparations: The transfer started in Sept. '14, } \\
\text { with a kick-off. Sender asked Receiver to secure } \\
\text { material from sub-suppliers without any formal } \\
\text { agreement. A significant amount of this material } \\
\text { became obsolete because of BOM changes, and } \\
\text { the financial consequences were unsettled for a } \\
\text { long time. The transfer was planned with par- } \\
\text { tially overlapped product development at Sender } \\
\text { and process development at Receiver. Often, } \\
\text { BOM and other product design changes came too } \\
\text { late (e.g. during continuous production instead of } \\
\text { the Pilot phase). } 4 \text { BOM changes were sent after } \\
\text { Receiver had ordered material. Moreover, Sender } \\
\text { had problems with own change control system } \\
\text { that did not allow purchasing materials for pro- } \\
\text { torred to Receiver. Later on, Sender may replace } \\
\text { totypes before design-freeze. Thus, many changes } \\
\text { '15, the production had been transferred from Re- } \\
\text { ceiver's Development department to Manuf. } \\
\text { tore unrecorded until Product Developer started } \\
\text { Re collect them in a common excel-file. [KT:] } \\
\text { No personnel from Receiver were transferred for } \\
\text { training at Sender. } \\
\text { Receiver appreciated having one contact person } \\
\text { at Sender (Product Developer) whereas Sender's } \\
\text { Prod. Developer felt that it had been challeng- } \\
\text { ing to know whom to contact at Receiver. She }\end{array}$ \\
\hline
\end{tabular}

dition, Receiver's performance should be monitored along the entire PT and measures should be implemented (A50) [4]. With respect to Case B, several authors stress the importance of a formal agreement (A12, A16) between parties, signed as early as possible during Preparations. The agreement should include each party's responsibilities along the process (e.g. who bears the cost of obsolete material), and desired performance targets (e.g. yield) [14]. Further, to effectively 
manage engineering changes, parties could also define the change control process (A24) during Preparations, and they could create a flow diagram of the PT with necessary decisions gates [4]. For instance, before starting with the continuous manufacturing, the production should have passed a verification gate (A45). Finally, with higher uncertainty of the PT (i.e. novelty, complexity, and tacit knowledge) there are higher requirements of interaction between parties (A18). For Case B, the For Case B, the assembly of product B was novel for the Receiver; the product version was an innovation, and it had a high amount of uncodified knowledge. Thus, parties could have invested more in information management systems (e.g. a common IT platform) and could have drawn advantage from the domestic proximity by having regular and more frequent meetings with the Receiver [23].

In this study, existing research on outsourcing processes is synthesized into one structured outsourcing procedure, comprising the outsourcing decision, the supplier selection, and the PT stage. We argue that one of the strengths of this procedure is providing a detailed overview of the PT specific activities, which are often overseen in earlier outsourcing procedures despite their impact on final performance results. The proposed procedure can guide practitioners in conducting production outsourcing processes in a systematic manner. Nevertheless, it should be validated in different manufacturing contexts and adapted to different types of production outsourcing. The authors objective for the future is to configure and validate a phase model comprising activities from the current procedure, decision gates, suggested disciplines for each activity, as well as appropriate methods and tools.

Acknowledgements This research has been conducted with support from the research project SoundChain funded by The Research Council of Norway. The authors would like to thank the project participants for providing valuable empirical data.

\section{References}

1. CAPS Research Organization: Outsourcing Strategically for Sustainable Competitive Advantage. Tempe (2005)

2. Kinkel, S., Maloca, S.: Drivers and Antecedents of Manufacturing Offshoring and Backshoring: A German Perspective. J Purch Supply Manag 15(3), 154-165 (2009)

3. Momme, J., Hvolby, H.: An Outsourcing Framework: Action Research in the Heavy Industry Sector. European Journal of Purchasing \& Supply Management 8(4), 185$196(2002)$

4. World Health Organization: Expert Committee on Specifications for Pharmaceutical Preparations,"Who Good Manufacturing Practices: Main Principles for Pharmaceutical Products. Tech. rep., World Health Organization (2011)

5. Kremic, T., Icmeli, T., Rom, W.: Outsourcing Decision Support: A Survey of Benefits, Risks, and Decision Factors. Supply Chain Manag 11(6), 467-482 (2002)

6. Fredriksson, A.: Materials Supply and Production Outsourcing. Chalmers University of Technology (2011) 
7. Madsen, E.S.: Knowledge Transfer in Global Production. Aalborg Universitet (2009)

8. Zeng, A.: Global Sourcing: Process and Design for Efficient Management. Supply Chain Manag 8(4), 367-379 (2003)

9. Baxter, P., Jack, S.: Qualitative Case Study Methodology: Study Design and Implementation for Novice Researchers. The Qualitative Report 13(4), 544-559 (2008)

10. Brandes, H., Lilliecreutz, J., Brege, S.: Outsourcing - success or Failure?: Findings from Five Case Studies. European Journal of Purchasing and Supply Management 3(2), 63-75 (1997)

11. Semini, M., Sjøbakk, B., Alfnes, E.: What to Offshore, What to Produce at Home? A Methodology. In: Emmanouilidis, C., Taisch, M., Kiritsis, D. (eds.) Advances in Production Management Systems. Competitive Manufacturing for Innovative Products and Services, pp. 479-486. No. 398 in IFIP Advances in Information and Communication Technology, Springer Berlin Heidelberg (2012)

12. Cousins, P., Lamming, R., Lawson, B., Squire, B.: Strategic Supply Management: Principles, Theories and Practice. Pearson Education (2008)

13. Danilovic, M., Winroth, M.: A Tentative Framework for Analyzing Integration in Collaborative Manufacturing Network Settings: A Case Study. J Eng Tech Manag 22(1), 141-158 (2005)

14. Terwiesch, C., Bohn, R., Chea, K.: International Product Transfer and Production Ramp-up: A Case Study from the Data Storage Industry. R Manag 31(4), 435-451 (2001)

15. Dudley, J.: Successful Technology Transfer Requires more than Technical Knowhow. Biopharm Int 19(10), 68-+ (2006)

16. Zhu, Z., Hsu, K., Lillie, J., Zhu, Z.: Outsourcing: A Strategic Move: The Process and the Ingredients for Success. Manag Decis 39(5), 373-378 (2001)

17. Fredriksson, A., Wänström, C., Johansson, M., Medbo, L.: A Structured Procedure for Materials Planning During Production Transfer. Prod Plann Contr 26(9), 738 $752(2015)$

18. Stock, G., Tatikonda, M.: A Typology of Project-level Technology Transfer Processes. J Oper Manag 18(6), 719-737 (2000)

19. Andre, M., Peter, B.: Towards a Framework for Transferring Technology Knowledge Between Facilities. Strategic Outsourcing: An International Journal 5(3), 213 $231(2012)$

20. Modi S.B., M.V.: Supplier Development: Improving Supplier Performance through Knowledge Transfer. J Oper Manag 25(1), 42-64 (2007)

21. Aaboen, L., Fredriksson, A.: The Relationship Development Aspect of Production Transfer. J Purch Supply Manag 22(1), 53-65 (2015)

22. Grant, E., Gregory, M.: Adapting Manufacturing Processes for International Transfer. Int J Oper Prod Manage 17(9-10), 994-1005 (1997)

23. Hilletofth, P., Wlazlak, P., Johansson, G., Säfsten, K.: Challenges with Industralization in a Supply Chain Network: A Supplier Perspective. In: MakeLearn and TIIM Joint International Conference. pp. 309-318 (2015)

24. McCormack, K., Wilkerson, T., Marrow, D., Davey, M., Shah, M., Yee, D.: Managing Risk in your Organization with the SCOR Methodology. The Supply Chain Council Risk Research Team pp. 1-32 (2008) 